\title{
1. Introduction to water issues and water accounting in Southern Africa
}

\section{Glenn-Marie Lange and Rashid Hassan}

\subsection{INTRODUCTION}

Global water demand has been growing rapidly over the past few decades owing to population growth as well as increasing per capita water demand. Between 1940 and 2000, withdrawals of freshwater have increased more than fourfold, despite improvements in water efficiency (WRI, 1996; 2005). Yet in developing countries the provision of water services still lags far behind the need. The Millennium Development Report indicates that 939 million people do not have access to safe drinking water worldwide and 2481 million are not provided with sanitation services (UN Millennium Project, 2005). The problem is most severe in Africa where 42 per cent of all people do not have safe drinking water (UN Millennium Task Force on Water and Sanitation, 2004).

Even though many people in the world still lack basic water services, water scarcity has been increasing in many parts of the world. With the supply of fresh water limited by the dynamics of the hydrological cycle, per capita water availability declines as population grows. Increased contamination by pollution has further reduced the supply of fresh water and increased the cost of treatment of available supplies. In much of North Africa and the Middle East, water use is more than 50 per cent of annual renewable supply of fresh water. Groundwater depletion is increasing on all continents and many countries rely increasingly on international water sources, creating a potential for conflict over water in the future. In addition, the scientific community expects climate change to have a major impact on the hydrological cycle, in ways that cannot be predicted at this time (Gleick, 2005).

As governments struggle to provide basic water services while global water scarcity increases, tough decisions about water allocation and infrastructure development will have to be made. But most countries are poorly equipped to anticipate and adapt to the economic consequences of increasing water scarcity because they lack sufficient information about water use 
and resources. Many countries compile some kind of database for water resources and water use; however, these databases are rarely integrated with economic accounts. Water accounting, an approach that integrates water accounts and economic accounts, provides that missing information and has a unique contribution to make to water management.

The purpose of water accounting is to increase knowledge about the interaction between water and human activity, providing a tool for improved water management. Population, the structure and level of economic activity, urbanization and increasing standards of living, land cover and land use changes all influence the availability of water and the use of water. Hence, a tool that links water supply and use with these factors is valuable for water management. Water accounts can identify:

- the consequences of economic growth and population growth for water use and availability

- the contribution of economic activities to particular environmental problems, such as overexploitation of groundwater, water pollution, or loss of biodiversity

- the economic implications (macroeconomic and sectoral) of water policy measures. Policies include those directly affecting water, such as water pricing, abstraction regulations and infrastructure development, as well as those indirectly affecting water such as agricultural development schemes, hydroelectric power development and urban concentration

The water accounts presented here for Botswana, Namibia, and South Africa provide a unique perspective on the economics of water supply and use, which can enable policy-makers to monitor not only the physical, but also the economic implications of water supply and water allocation. The economic analysis enables policy-makers to make a more informed choice regarding the infrastructure development and the efficient allocation of water to different economic activities. In addition, the water flow accounts can be combined with economic models to explore the impacts of alternative water policies, such as the impact on water demand of price increases, or the introduction of water conservation technologies.

The water accounts in southern Africa have been developed over the past 10 years as a major component of a regional initiative to construct environmental accounts in Africa. The initiative began in Botswana, Namibia and South Africa, and has recently expanded to Tanzania, Uganda and Mozambique, with the prospect of including additional countries in the future. This book updates and greatly expands a chapter on water accounts written by the authors in an earlier book on environmental accounting in 
southern Africa (Lange et al., 2003). Water is such a critical and complex issue, globally and in southern Africa, that a comprehensive analysis of water accounts requires book-length treatment.

The water accounts for Botswana, Namibia and South Africa are presented in this book, based on a range of primary and secondary data, much of which has never been formally published before. The emphasis of the book is to show how the water accounts have actually been implemented and how they can be used to influence policy decisions at national and regional levels.

The next section of this chapter provides an overview of the water resources and economies of Botswana, Namibia and South Africa. Section 1.3 introduces the general structure and methods of constructing water accounts provided by the SEEA (UN et al., 2003). The detailed framework and methodologies, such as the classification of water providers or types of water, will vary by country, and will be discussed in the relevant country chapters. The final section outlines the plan of the book.

\subsection{WATER RESOURCES OF BOTSWANA, NAMIBIA AND SOUTH AFRICA}

Water is often cited as one of the major constraints to development in Namibia, Botswana and South Africa. Of the three countries, Namibia is sub-Saharan Africa's driest country; roughly 80 per cent of its 842000 square kilometres consist of desert, arid and semi-arid land (Brown, 1994; Pallett, 1997). Rainfall is quite low, ranging from less than $25 \mathrm{~mm}$ along the western coast to more than $700 \mathrm{~mm}$ a year in the north-east with a longterm average of about $250 \mathrm{~mm}$ per year (Pallett, 1997), less than the minimum amount considered necessary for dryland farming $(400 \mathrm{~mm}$ a year). Rainfall is not only low but extremely variable and droughts are a common occurrence. In addition, Namibia's high temperatures result in high rates of evaporation of rainfall; it is estimated that only 1 per cent of annual rainfall contributes to groundwater recharge and only 2 per cent is retained in reservoirs (DWA, 1991). Botswana has a very similar climate with a somewhat higher average rainfall, $400 \mathrm{~mm}$ per year (Pallett, 1997). South Africa is a much larger country with a more varied climate, but its average annual rainfall is still only $500 \mathrm{~mm}$. South Africa is projected to achieve the status of acute water stress in the near future, a situation where annual renewable water resources fall below 1000 cubic metres (WRI, 1996).

Water use has grown rapidly over the last 25 years in Southern Africa as a result of population and economic growth. Annual per capita water use ranges from a low of $103 \mathrm{~m}^{3}$ in Botswana to a high of $295 \mathrm{~m}^{3}$ in South Africa 
Table 1.1 Population, water use and economy of Botswana, Namibia and South Africa in 2000

\begin{tabular}{lccc}
\hline & Botswana & Namibia & South Africa \\
\hline Area of country (thousands of $\mathrm{km}^{2}$ ) & 582 & 842 & 1221 \\
Population (millions) & 1.6 & 1.8 & 43.7 \\
\% Urban & $50 \%$ & $31 \%$ & $59 \%$ \\
\% Rural & $50 \%$ & $69 \%$ & $41 \%$ \\
Total freshwater use (million $\mathrm{m}^{3}$ ) & 169 & 266 & 12873 \\
Per capita water use & 103 & 149 & 295 \\
GDP (in millions of currency units) & Pula 29353 & $\mathrm{~N} \$ 24601$ & Rand 838218 \\
GDP (millions of US\$) & US\$5341 & US\$3241 & US\$110437 \\
GDP (US\$ per capita) & 3257 & 1821 & 2528 \\
Structure of GDP (at basic prices, & & & \\
$\quad \%$ of total) & 3 & & \\
Agriculture, forestry, fisheries & 38 & 11 & 3 \\
Mining & 5 & 10 & 19 \\
Manufacturing & 9 & 5 & 5 \\
Utilities and construction & 28 & 38 & 49 \\
Services excluding government & 17 & 23 & 16 \\
Government & 100 & 100 & 100 \\
Total & & & \\
\hline
\end{tabular}

Sources: water data: Bank of Botswana, 2005: ch. 5; CBS, 2005; Statistics South Africa website, www.statssa.gov.za, accessed October 2005.

in 2000 (Table 1.1). There is concern that water supplies are not being used sustainably. Water scarcity has international repercussions because every country in Southern Africa relies to varying degrees on shared international rivers. Water management in South Africa and Namibia must also address the legacy of the apartheid period, which resulted in unequal development of and access to water resources.

In the past, water management authorities approached water scarcity almost exclusively as a supply problem to be solved by feats of engineering. Very little attention was paid to the economic aspects of water use and to managing the demand for water through economic incentives for water conservation. Both South Africa and Namibia have revised their water acts and place a new emphasis on economic aspects of water management in supply, allocation and pricing policies. Botswana is developing a new Water Master Plan that will also consider economic aspects of water management.

There is no single, central authority responsible for all aspects of water in any of the three countries. Each country has a Department of Water Affairs (DWA), but responsibility for management is partly dispersed 
among other agencies as well. Similarly, there is no central institution responsible for water supply; rather, a number of different institutions provide water in each country. Some of these institutions rely on a relatively large-scale, technologically sophisticated infrastructure for collection and long-distance water distribution networks, while others rely mostly on local, small-scale infrastructure such as local boreholes and small dams. In Botswana and Namibia, self-providers account for a large share of water supply and use. Water authorities have often focused on the formal institutions that provide water to other users, leaving the self-providers relatively lightly monitored and regulated. Consequently, a large share of water use may occur outside the formal management structure and outside the framework of water policy.

Despite these challenges, all three countries have achieved high rates of access to safe drinking water and sanitation, far greater than the average for Africa (Figure 1.1). Nearly 100 per cent of the urban population has access to safe drinking water and at least 75 per cent of the rural population. Access to sanitation is much lower but has been improving, albeit slowly.

Water use is heavily influenced by the structure of the economy, population, and the level of economic development. All three countries are middle-income countries. Botswana and South Africa also have relatively high urbanized populations (50 per cent or more), which typically use more water than the rural population (Table 1.1).

Botswana and Namibia are rather similar in size and population compared with South Africa, which is larger by an order of magnitude. Their sparse population reflects very low average rainfall and relatively poor agricultural conditions. Historically, the land did not support large populations and most of the land is now used for extensive livestock grazing and wildlife conservation areas which form the basis for tourism, a major industry in all three countries. While South Africa's average rainfall is also low, it is considerably higher than Botswana or Namibia; its agricultural potential is also higher.

Primary sector activity dominates the 2000 gross domestic product (GDP) of Botswana (41 per cent) and Namibia (20 per cent) but is much smaller in South Africa (11 per cent). However if the processing of primary products is added, South Africa joins the other two countries as an economy highly dependent on natural resources. With its more highly developed economy, South Africa carries out much more processing of materials - mainly agriculture, wood and minerals - than the other two. Botswana processes very little of its primary products; in Namibia, processing of livestock and fish is a major component of GDP. 


\section{A. Access to safe drinking water}

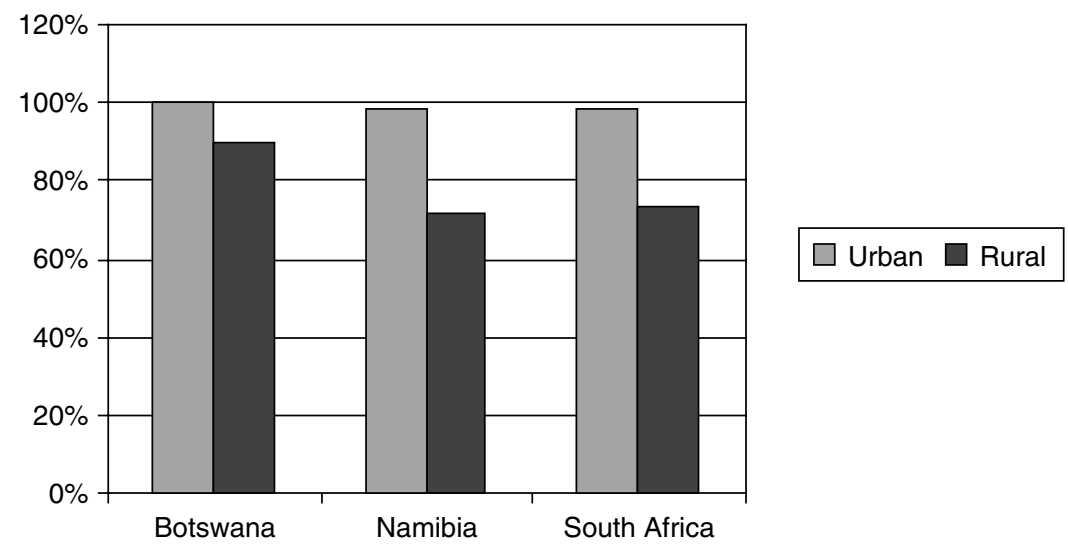

B. Access to sanitation

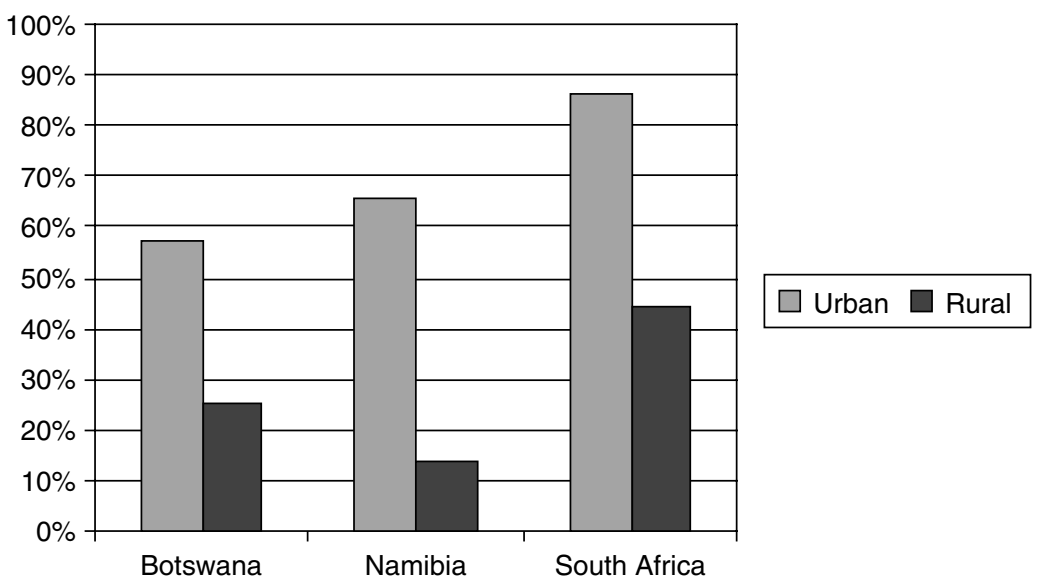

Source: website of UN Statistics Division, www.unstata.un.org/unsd/mi/mi_goals.asp, accessed October 2005.

Figure 1.1 Access to safe drinking water and sanitation in Botswana, Namibia and South Africa, 2002 


\subsection{METHODOLOGY: THE SYSTEM OF ENVIRONMENTAL AND ECONOMIC ACCOUNTING FOR WATER}

Environmental and natural resource accounting began in the 1970s and continued through the 1980s through the efforts of individual countries and practitioners, each developing their own frameworks and methodologies to represent their environmental priorities. Since the late 1980s, the United Nations Statistics Division, Eurostat, the Organisation for Economic Co-operation and Development (OECD), the World Bank, national statistical offices and other organizations undertook an effort to standardize the framework and methodologies, under the aegis of the London Group, a group established by the United Nations Statistical Commission for environmental accounting. In 1993, the first, interim handbook was published, the SEEA (UN, 1993). This was followed by a decade of conceptual work and empirical applications by national and international agencies, academics and non-governmental organizations (NGOs) resulting in a substantially revised and expanded SEEA handbook in 2003 (UN et al., 2003).

Water resources were not treated in much detail in the SEEA, mainly because the complexity of water accounting could not be fully addressed in a handbook that had to include all natural resources. A specialized manual for water accounting, the SEEAW is being written to address all aspects of water: supply and use of water, wastewater, water pollution and stocks of water (volume and quality); both physical and monetary accounts are included (UN, 2005).

The SEEAW provides a comprehensive framework for incorporating the role of water in the economy through a system of satellite accounts to the national accounts - accounts that are linked to the national accounts through a common set of definitions and classifications, but which do not affect the core values of the national accounts. Satellite accounts are developed when information in the conventional national accounts is not presented in the manner required for policy analysis. There are, for example, satellite accounts for tourism and for transportation.

The SEEAW describes most of the hydrological cycle, from precipitation and soil water to the abstraction and use of water for human activities, and the returns of wastewater, treated or untreated, back to the environment. The water accounts include the following main components:

- Water flow accounts record the flows of water between the economy and the environment, including the supply, use and returns of water by industry and households. These are usually organized in the 
format of a supply and use table (SUT) that is similar to the SUT compiled for national income accounts. The main tables include:

- physical water flow accounts that record the volume of water supplied by an agent either for own use or for delivery to another user, and the volume used by industry and households

- monetary water flow accounts that record the cost of delivering water to the user and the tariff charged for that water; the difference between the two being the effective water subsidy

- wastewater accounts, the component of the SUT that records the volume of wastewater discharged after use. Monetary wastewater accounts record the cost of treating wastewater and the user charge for wastewater treatment.

Water is used both directly and indirectly. Direct uses represented in the SEEA water accounts include agriculture, manufacturing, services, hydroelectric power production, human consumption and sanitation. Recreation and navigation are direct uses, not included at this time. Indirect uses include water required for the transport of water from one place to another, and support of ecosystem health. These are also not included in the water accounts, although a number of countries are including an environmental requirement in their accounts (for example, Australia, South Africa).

- Emission accounts record the volume of pollution emitted to a water body. Monetary accounts record discharge fees, if any, for wastewater. Water pollution can also be measured in monetary terms as the cost of damage caused.

- Water asset accounts report the amount of the total resource and changes in the resource over the accounting period (usually a year, although in the case of surface water, a case can be made for seasonal stock accounts). Groundwater resources, lakes and dam storage correspond reasonably well to the stock concept, although it is often difficult to establish empirically the volume of groundwater and its recharge rate. However, surface water, mainly rivers, does not fit easily into the concept of a stock, being partly a flow and partly a stock concept. Consequently, countries have developed a range of supplementary indicators to assess the volume of resource available. The water stocks also include a measure of water quality, although this element has not yet been fully developed in the SEEAW.

In principle, stocks of water can be valued like any other asset, but there is currently only one example, from New Zealand - the value of water stored by dams for the sole purpose of generating hydroelectric power. Water valuation, discussed in Chapter 7, is very 
challenging and has not yet been applied to water accounts, except on a case study basis.

- Water value. The natural characteristics of water have prevented the emergence of a competitive market for water in the vast majority of uses, so there is often no market price that reflects the economic value of water. Observed tariffs are usually set administratively on the basis of supply cost or on the basis of affordability in order to ensure that water is available to the majority, if not all, people. Consequently, the observed prices are not a useful guide to policy-makers trying to assess the economic value of water in different uses.

Virtually all international water organizations have embraced the notion of water as an economic good (see Chapter 7), and recommend that water management and infrastructure planning take into account the economic valuation of water. However, no country's water accounts have yet included valuation except on a case study basis. Water valuation is discussed in the SEEAW at some length, but it is clear that water valuation is not likely to be widely applied in the near future.

The SEEAW is a vast, comprehensive manual, and no country has yet implemented all components of the SEEAW (Table 1.2). All countries start with the physical water supply and use table, usually with greatest emphasis on the use accounts because these were found most useful for policy analysis. In countries where pollution is important, wastewater and pollution accounts were also compiled early on. The monetary accounts are also quite important for water policy, and many countries have compiled at least partial monetary accounts, but data have been more difficult to obtain than for the physical accounts.

Botswana, Namibia and South Africa also started with the physical flow accounts, monetary flow accounts and some indicators of water stocks. Monetary accounts are very limited owing to lack of data. Incomplete data prevent a thorough reporting of water stocks, although some information and indicators of water stocks and availability have been compiled. Wastewater has not yet been addressed in the water accounts, except to a limited degree in Botswana. Water pollution is not a serious issue in Botswana or Namibia except for some localized occurrences. It is a larger problem in South Africa, but has not yet been addressed in the water accounts.

Although all three countries used the SEEAW, the water flow accounts differ in their emphasis, largely because of data availability. Botswana's water use accounts are not as detailed as the first water accounts (see Lange et al., 2003); a separate water supply table has not yet been developed, but is planned for the next stage of the work. Namibia's accounts provide the 
Table 1.2 Countries that have constructed water accounts

\begin{tabular}{|c|c|c|c|c|}
\hline & \multicolumn{4}{|c|}{ Flow accounts } \\
\hline & $\begin{array}{c}\text { Stock } \\
\text { accounts }\end{array}$ & Physical & Monetary* & $\begin{array}{l}\text { Waste water } \\
\text { and pollution }\end{array}$ \\
\hline \multicolumn{5}{|c|}{ Developed countries } \\
\hline Australia & Partial & $X$ & & $X$ \\
\hline Denmark & & $\mathrm{X}$ & $\mathrm{X}$ & $\mathrm{X}$ \\
\hline France & Partial & $X$ & $X$ & $X$ \\
\hline Germany & & $\mathrm{X}$ & & $\mathrm{X}$ \\
\hline Netherlands & & $\mathrm{X}$ & $\mathrm{X}$ & $\mathrm{X}$ \\
\hline New Zealand & & $\mathrm{X}$ & $\mathrm{X}$ & \\
\hline Spain & Partial & $\mathrm{X}$ & $\mathrm{X}$ & \\
\hline Sweden & & $X$ & $X$ & $X$ \\
\hline \multicolumn{5}{|c|}{ Developing countries } \\
\hline Botswana & Partial & $\mathrm{X}$ & $\mathrm{X}$ & \\
\hline Chile & Partial & $\mathrm{X}$ & $\mathrm{X}$ & \\
\hline Moldova & & $\mathrm{X}$ & $\mathrm{X}$ & $\mathrm{X}$ \\
\hline Namibia & Partial & $X$ & $\mathrm{X}$ & \\
\hline Philippines & & $\mathrm{X}$ & $\mathrm{X}$ & $X$ \\
\hline South Africa & Partial & $\mathrm{X}$ & $\mathrm{X}$ & \\
\hline \multicolumn{5}{|c|}{$\begin{array}{l}\text { Planning to develop } \\
\text { water accounts }\end{array}$} \\
\hline Tanzania & & $\mathrm{X}$ & $\mathrm{X}$ & \\
\hline Mozambique & & $\mathrm{X}$ & $\mathrm{X}$ & \\
\hline China & & $X$ & $\mathrm{X}$ & $\mathrm{X}$ \\
\hline
\end{tabular}

Notes:

Economic valuation has only been carried out in local case studies (for example, Namibia and South Africa) and for water stored in dams for hydroelectric generation (New Zealand). * Monetary accounts include the cost of supply and the tariff paid, but may not be very detailed in some countries.

most detailed SUT for water, but flows between the environment and economy are limited to abstractions by users. In South Africa, an effort was made to follow the SEEAW in its entirety, using data already collected by government for other purposes. Consequently, the water resources accounts are well developed, but the use accounts are not as detailed as the Namibian accounts.

Regarding water value, some case studies were conducted as part of water accounting because this is a critical issue for water management. Water quality is a concern, but the accounting framework for water quality is still rather experimental and difficult to implement; none of the three countries plan to implement water quality accounts in the near future. 


\subsection{PLAN OF THE BOOK}

In addition to the introduction, the book has three parts. The first part has three chapters (Chapters 2-4) that present the water accounts for each country, a discussion of water resources and water policy, and an in-depth analysis of the national water accounts. Part II includes two chapters that address major regional water policy issues. Chapter 5 extracts from the preceding chapters the parts of the water accounts that are comparable across countries. The chapter compares the countries for macroeconomic trends in economic growth and water use, sectoral water productivity, and the monetary accounts: the degree to which each country subsidizes water. Water productivity is generally highest at the macroeconomic and sectoral levels in Botswana, which also appears to provide the least subsidies. Chapter 6 analyses the water content of traded goods and services in the three countries to determine whether each country is a net importer or a net exporter of water. Given water scarcity, one would expect these countries to be net water importers, that is, the products they import would have a higher water content than products they export. This is the case for Botswana and Namibia, but not for South Africa.

The final part of the book addresses a critical issue: economic valuation of water. Chapter 7 provides a theoretical and empirical overview of water valuation techniques used by economists; the next two chapters present water valuation case studies in Namibia and South Africa, respectively. Water value varies considerably by region and by use; in some agricultural uses the value does not even cover the cost of supply. No studies have yet been carried out for Botswana. 
Glenn-Marie Lange and Rashid Hassan - 9781847203021 Downloaded from PubFactory at 04/26/2023 01:03:43PM via free access 